\title{
Effects of Chronic Ethanol Treatment on Neocortex
}

\author{
Lester T. Rutledge, PhD, Mark A. Sutter, MA, Shu-ing Chi, DDS, and Todd A. Gray, BA
}

\begin{abstract}
Neocortical inhibition and neuronal morphology were studied in rats following chronic othanol treatmemt (CET). In terminal acute experiments, spontaneous neuronal discharges in pair-ted and naive rats were inhibited by epicortical stimulation, a procedure known to produce postsynaptic inhibition. Few units in CET rats were inhibited by such stimulation. Cortical recurrent inhibition, indicated by a surface-negative potential in response to antidromic stimulation of the cerebral peduncte, was little affected by a challenge dose of ethanol, compared with the response in pair-fed animals. Recurrent inhibition involves inhibitory interneurons. CET apparently made inhibitory interneurons and inhibitory postsynaptic receptors less responsive to ethanol. Apical dendritic spines on some portions of pyramidal neurons increased in number with CET. This could reflect a compensatory growth in neurons not damaged by CET. The overall obeervations are consistent with ethanol affecting one or more specific systems of cortical motor control as opposed to its presumed general disinhibitory effect.
\end{abstract}

$\mathbf{T}$ THE EXPERIMENTS reported here are extensions of those on the effects of acutely administered ethanol described in the preceding paper. ${ }^{1}$ Experiments were designed to evaluate neocortical effects of chronic ethanol treatment (CET) on 1) spontaneously firing neurons during epicortical stimulation, 2) an antidromically elicited cortical field potential, and 3) neuronal dendritic and spine morphology. Since experiments of this kind have not been reported until now, the results from an initial group of animals could guide direction for more extensive work.

There have been few reports on neuronal unit activity in primary projection areas of neocortex in animals given ethanol acutely. Ethanol ejected from micropipettes onto spontaneously discharging somatosensory cells in unanesthetized rats decreased firing rates in $23 \%$, increased rates in $10 \%$, and $65 \%$ were unaffected. ${ }^{2}$ Similar experiments showed that of 13 cortical cells, 9 were unresponsive to ethanol and the rest were excited. ${ }^{3}$ Multiple unit activity in unanesthetized rabbits was especially responsive to intraperitoneal injections of ethanol. ${ }^{4}$ Ethanol reduced or abolished the suppression of input to particular cortical neurons during phases of the locomotor step cycle. ${ }^{5}$ The inhibitory effect of surface stimulation on neuronal firing

From the Department of Physiology. The University of Michigan Medical School. Ann Arbor, Michigan.

Received for publication October 14, 1985; revised manuscript received January 21, 1986; accepted March 6. 1986

This work was supported by Gramt 05979 from the National Institute on Alcohol Abuse and Alcoholism.

Reprint requests: Dr. L. T. Rutledge, Department of Physiology. Medical Science Building. The University of Michigan Medical School, Ann Arbor. MI 48109

Copyright $@ 1986$ by The American Medical Society on Alcoholism and The Research Society on Alcoholism. was potentiated by local injection of ethanol, and $\gamma$ aminobutyric acid inhibition was potentiated. ${ }^{6,7}$ No reports of neocortical neuronal activity after CET have been found, but other areas have been investigated. Studies on cortical neuronal morphology in cerebellum, cingulate gyrus, and hippocampus after CET have been reported. ${ }^{8-14}$ In a short report, ${ }^{15}$ CET in rats apparently caused neuronal degenerative changes and compensatory neuronal dendritic spine increases in neocortex. Also in rats, ethanol produced destructive effects on the cytoplasm of neocortical neurons. ${ }^{16}$

The results of the experiments reported here support our contention in the preceding paper that a primary effect of ethanol on neocortex is on neuronal inhibitory mechanisms. They are much less definitive in regards to ethanol effects upon neocortical neuronal morphology.

\section{METHODS}

In the various parts of this study, 23 male Sprague-Dawley rats (Charles River) were used. All were about 220 days of age at time of terminal acute experiments or death for histological study. Of the total, 12 were assigned to the CET (4 rats), pair-fed (4 rats) and chow-fed (4 rats) groups. The remaining 11 were obtained at about 205 days of age and kept in the animal colony on standard lab pellets and water, ad libitum, until used for acute experiments.

\section{Electrophysiology}

Unit Recordings. Terminal acute experiments were conducted on 10 rats anesthetized with ketamine and zylazine.' Four were naive controls and two each from CET, pair-fed, and control groups. An animal's head was fixed in a headholder and the mid-dorsal region of the neocortex was exposed under mineral oil. Oil pool and body temperatures were maintained by heating elements. For extracellular unit recordings, insulated tungsten microelectrodes (5-25 $\mu \mathrm{m}$ exposed tips) were advanced vertically through the cortex with a hydraulic microdrive. Standard electrophysiological equipment included a window discriminator which counted the voltage signals generated by spike discharges in ten 50 -msec time bins. Successive sweeps (usually 20-40), locked to a time signal, permitted bin accumulations of neuronal discharges during control (spontaneous firing) and cortical stimulation periods, and gave histograms displays with absolute bin values. Final recordings were not made until a unit's firing was stable for at least $10 \mathrm{~min}$. Epiconical stimulation via bipolar silver ball electrodes spaced at $1.5 \mathrm{~mm}$, and located within 2 $\mathrm{mm}$ of the microelectrode, was used to determine inhibitory and excitatory effects upon cell discharge. ${ }^{17,18}$ Epicortical stimulation was usually a single pulse of $0.1-0.2-\mathrm{msec}$ duration, less than $1.0 \mathrm{~mA}$ at $0.5 \mathrm{~Hz}$.

Peristimulus and poststimulus time histograms of neuronal spike discharges are not usually subjected to statistical treatment. We have followed the statistical procedure of Dörrscheidt ${ }^{19}$ where the spike distribution is assumed to have a Poisson pattern typical of a randomly occurring process. A "goodness of fit" test was applied to the control (spontaneous firing) spike distributions and in all instances the spike counts were found to be randomly distributed in the 10 bins after 20 or 
more repetitions. Confidence intervals for the difference between stimulated bin entries and the control rate were found in tables for the distribution of a Poisson variable. ${ }^{20.21}$ This statistical treatment permits a description of each bin entry deviation from control in terms of a probability level. Each neuron discharge was then characterized as to whether and when spike activity changed during the $500 \mathrm{msec}$ after epicortical stimulation. Illustrated in Fig. I are three categories of neuronal discharges following stimulation and the probability level of difference from control.

Antidromic Potential. In the preceding paper,' we described a field potential, the surface-negative (SN) wave, antidromically evoked by stimulation of the ipsilateral cerebral peduncle. The $\mathrm{SN}$ wave is a summation of inhibitory postsynaptic potentials (IPSPS) in deep-lying somas and proximal dendrites and represents a measure of cortical recurrent inhibition (RI). Acutely administered ethanol depressed $\mathrm{SN}$ wave amplitude.' The SN wave was now studied after challenge doses of ethanol in acute experiments following CET. Studies were done on two CET and two pair-fed rats I week afier the conclusion of 20.5 weeks of CET. Preparation under ketamine and xylazine was as described in the preceding paper.'

\section{Morphology}

Data were obtained from 13 rats, including the two CET and two pair-fed controls used in the SN wave study. The aim was to evaluate dendritic branching and spines of neocortical pyramidal cells. The rapid Golgi method of staining was used. ${ }^{22}$ Tissue blocks of about $50 \mathrm{~mm}^{3}$ were removed from the sensorimotor cortex after head perfusion with saline and buffered formalin. Coronal sections from celloidin-embedded tissue were cut at $125 \mu \mathrm{m}$, placed on slides, and cover-slipped. Processed along with the experimental material were blocks of tissue from the naive controls. Slides were coded, until the study was completed, to cover the identity of the animals. Selected for study were pyramidal neurons, in layers lower II to V, with apical dendrites extending into at least layer II. Criteria for study were: cells had to show uniform staining of neuronal processes (except axons); there was absence of debris or precipitate on cell membranes and background; good contrast between cells and background was necessary; and sections had to be of uniform thickness. These criteria were difficult to meet and resulted in a small number of cells which could be studied in each animal. Two kinds of measurements were made from scaled drawings: basal and apical dendritic branches in $50-\mu \mathrm{m}$ concentric circles (from soma), and spine counts in $20-\mu \mathrm{m}$ sections on basal dendrites. the midportion of the main apical shaft, oblique branches, and terminal sections of dendrites about $100 \mu \mathrm{m}$ from the pial surface: Data were treated with the Mann-Whitney U-test. ${ }^{23}$

\section{CET}

Twelve rats were received at 52-54 days of age, randomly assigned to one of the three groups (CET, pair-fed, or control), and maintained on ad libitum lab chow pellets and water in individual cages for 2 weeks. Four CET rats and four pair-fed controls were then placed on a liquid diet (Bio-Mix, Bio-Serv, Inc., Frenchtown, NJ). The CET rats were fed increasing amounts of ethanol over the first 10 days until the diet contained $35 \%$ ethanol-derived calories. After 16 weeks the ethanol and sucrose caloric equivalents were increased to $38 \%$ to offset partially the tendency of rats to reduce slightly their ethanol consumption as their body weights increase. ${ }^{10}$ The total CET was 20.5 weeks. During the last 10 days of CET, diet ethanol was reduced from $38 \%$ to $28 \%$ ( 5 days), and then to $19 \%$ (last 5 days), in order to prevent withdrawal symptoms, including possible seizures and death. Even in the absence of motor seizures, abnormalities in brain function, as might be shown by spiking in the electroencephalogram, can occur within several days following abrupt ethanol withdrawal. We therefore waited 10 days before the acute experiments during which the rats were on ad libitum lab chow. Two blood alcohol levels were determined at 5 and $91 / 2$ weeks, in the afternoon, using blood from the tail and an enzymatic method' (Sigma, Procedure No. 332-UV).

\section{RESULTS}

\section{Animals}

Average body weights of ethanol and pair-fed rats differed by only $1-7 \%$ during CET, and during the 12 th to the 20th weeks of pair-fed rats weighed the same as the lab chow controls. Ethanol consumption was 7.8-11.1 $\mathrm{g} / \mathrm{kg} /$ day, somewhat lower than that reported by others. Blood alcohol levels averaged 100 and $90 \mathrm{mg} / 100 \mathrm{ml}$ for the two measurements. Liver weight to body weight ratios of the groups did not differ.

\section{Electrophysiology}

Unit Recordings. Fig. 1 illustrates how each neuron's discharge was classified following epicortical stimulation. A probability of 0.05 or better was accepted as showing a difference from the control, spontaneous rate. Complete recordings were obtained from 61 neurons of which 18 were from CET rats. Since the effect of epicortical stimulation on neurons among pair-fed, lab chow control, and naive control rats did not differ, the data are all included as those from "control." The proportions of cells placed in the various categories are shown in Fig. 2. Significantly fewer cells from CET rats were inhibited by epicortical stimulation within $500 \mathrm{msec}$ and more cells were excited, compared with cells from control animals $(p=0.049)$. The effects of loss of inhibition and increased excitation in cells from CET rats are even more convincing $(p=$ 0.012 , Fig. 3) when the poststimulus analysis period is restricted to the first $150 \mathrm{msec}$ (Fig. 3). During this time no cells from CET rats were inhibited (Fig. 3).

Antidromic Potential. When the SN wave was elicited by dual cerebral peduncle shocks, $25 \mathrm{msec}$ apart, the response to the second shock was nearly totally blocked (from baseline) in a control animal (Fig. 4), but at the same intershock interval the second $S N$ wave in a CET rat was little affected. Fig. 5 shows $\mathrm{SN}$ wave amplitudes as a function of dual shock intervals in a pair-fed and a CET rat and the change following challenge doses of ethanol to the latter. Throughout the range of shock intervals, the SN curve for the CET rat was shifted to the left indicating that the RI circuit was less responsive to the summative effects of a second cerebral peduncle shock than it was in a nonethanol-treated rat. Two challenge doses of ethanol to the CET rat brought the amplitude of the $\mathrm{SN}$ wave in response to the second shock (interval $25 \mathrm{msec}$ ) right to the point of nearly total block seen in the pair-fed animal's record. Ethanol had little effect on SN wave amplitude in response to the first shock.

\section{Morphology}

Although some 50 neurons were studied in 13 animals only 12 from CET and pair-fed animals met the rigorous criteria for selection and therefore the results can only be considered as suggestive of possible ethanol effects. No 

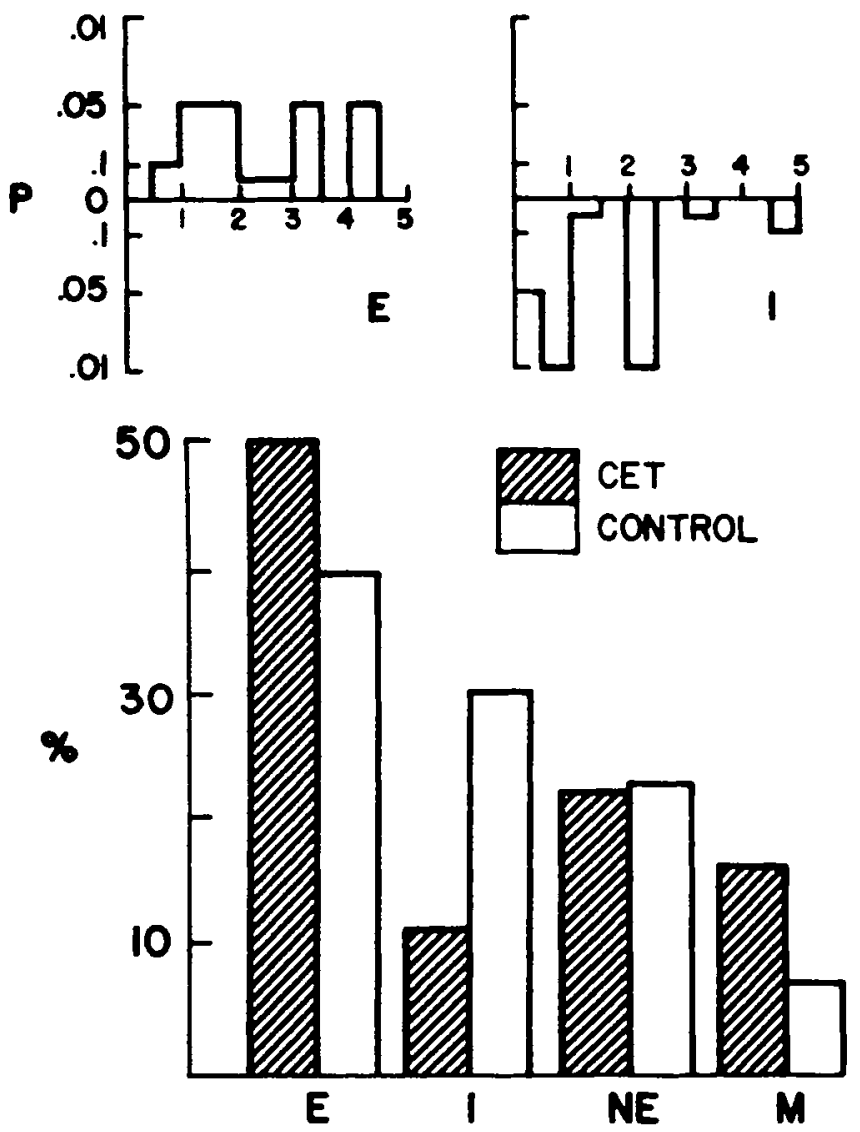

Fig. 2. Percentages of from CET and control animals classed as excited (E), intibited (I). no effect (NE), or mixed (M) during $500 \mathrm{msec}$ after epicortical stimulation. Differences between CET and control for $E$ and $I: p=0.0486$ (signifcance test, binomial distribution).

changes between basal and apical dendritic branching at different distances from the somas were found. Similarly, no differences were found in numbers of dendritic spines on basal and oblique dendrites. However, the mean of ranks for spines on main apical shafts (7.10 CET, 5.08 pair-fed) and terminal dendrites (7.67 CET, 4.00 pair-fed) was significantly greater for cells from CET rats (0.05 and 0.001 levels, respectively).

\section{DISCUSSION}

A main conclusion of this study was that CET resulted in a marked change in neocortical inhibitory functions. It has been found in several studies on cats that a single

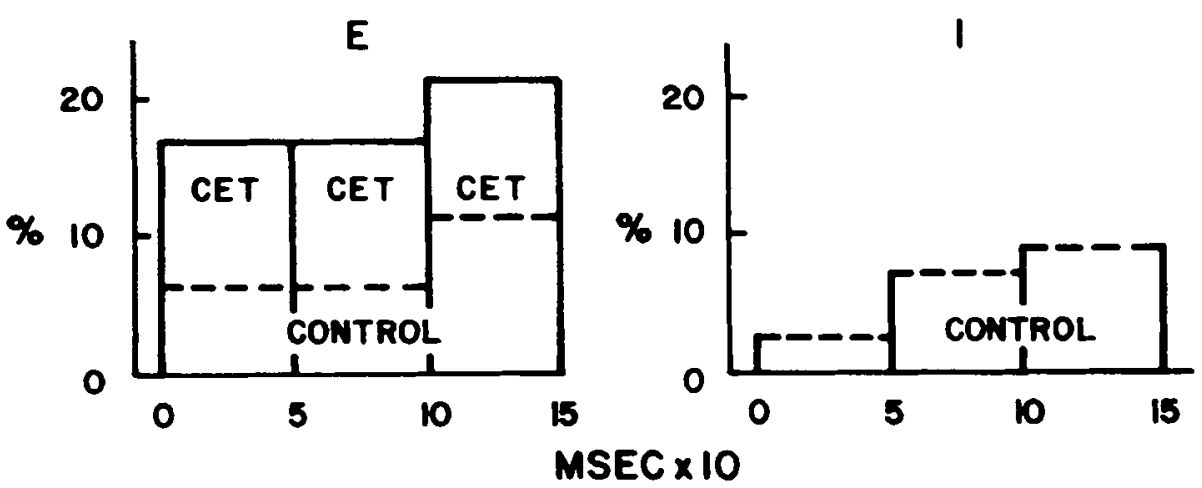
tions.
Fig. 1. Three main types of neuronal discharges during $500 \mathrm{msec}$ following epicortical stimulation. Height of bers indicated on ordinate as probablity of spike discherge being different trom spontaneous period. Excitation above zero ine, intibition below. $E$. excitatory; I, inhibitory; M mixed. Time base: $\mathrm{msec} \times$ 100.

electrical stimulus applied to the cortical surface inhibited spontaneous firing of cortical neurons below the surface electrodes. ${ }^{17,18,24,25}$ The basis for the effect are IPSPs produced by the stimulation, presumably involving interneurons. Direct application of ethanol, to a neuron whose discharge was slowed by cortical stimulation, decreased the discharge further and this inhibition was thought to be $\gamma$-aminobutyric acid-mediated. ${ }^{6,7}$ Presynaptic inhibition in amphibian spinal cord, involving $\gamma$-aminobutyric acid, was potentiated by the addition of ethanol to the perfusate. ${ }^{26}$ At low doses of ethanol in acute rat preparations, there was a mixture of excitation and inhibition on spontaneous firing of hippocampal neurons and as doses increased inhibition of discharge prevailed. ${ }^{27}$ In our experiments CET resulted in failure of epicortical stimulation to produce strong neuronal inhibition. The possible role of $\gamma$-aminobutyric acid-mediated inhibition in explaining our observations is unclear. Walker et al. ${ }^{28}$ also suggested that CET has an effect upon neuronal inhibition. The cellular mechanism for block of inhibitory synapses is unknown, but Durand and Carlen ${ }^{29}$ theorized that ethanol exposure could lead to a chronic impairment of $\mathrm{Ca}^{2+}$-mediated potassium conductance. This could reduce or block the generation of IPSPs. Acute effects of ethanol on cortex are likely different from the chronic ones. Until shown otherwise, it is also best to assume that biphasicity of effects may be found under both experimental condi-

A caution is in order. The results of our unit studies are clear in showing a loss of cortical inhibition by epicortical stimulation after CET, but there is no way of proving that the sample of cells obtained from CET rats came from the same population as those sampled in control animals. There is thus a possibility that "different" cells were being

Fig. 3. Percentages of colls from CET and control animats excited (E) or inhibited (I) during first $150 \mathrm{msec}$ alter epicortical stimukation. No colts from CET animats were inhibited within $150 \mathrm{msec}$. Differences between CET and control: $p=0.0122$ (significance test, binomial distribution). 
higher. Alternatively, fresh tobacco smoke contains about $50 \mu \mathrm{M}$ acetaldehyde at 1 atm between $20-37^{\circ} \mathrm{C}^{\gamma-8}$ and chronic alcohol consumption increases the rise in blood acetaldehyde levels that follows the ingestion of ethanol. ${ }^{24}$ Thus, the combination of drinking and smoking could result in acetaldehyde concentrations similar to those (50 or more $\mu \mathrm{M}$ ) which produce metaplasia of tracheal epithelium when inhaled by experimental animals. ${ }^{7.8}$ The local acetaldehyde concentrations are expected to be even higher in those normally septic areas, such as the oropharynx,${ }^{13}$ where the strongest synergism between alcohol and smoking on carcinogenesis has been found. ${ }^{1-3}$ Even if the concentrations were smaller than those used in experimental animals, possible effects due to prolonged exposure to acetaldehyde in alcoholics who smoke should be considered as a possible factor in the synergism between alcohol and tobacco in the pathogenesis of upper respiratory cancer.

\section{REFERENCES}

1. Rothman K, Keller A: The effect of joint exposure to alcohol and tobacco on risk of cancer of the mouth and pharynx. J Chronic Dis 25:711-716, 1972

2. Wynder EL, Mushinski MH, Spivak JC: Tobacco and alcohol consumption in relation to the development of multiple primary cancers. Cancer 40:1872-1878, 1977

3. Flanders WD. Rothman KJ: Interaction of alcohol and tobacco in laryngeal cancer. Am J Epidemiol 115:371-379, 1982

4. Schmidt W, Popham RE: The role of drinking and smoking in mortality from cancer and other causes in male alcoholics. Cancer 47:1031-1041, 1981

5. Herity B, Moriarty M, Daly L, Dunn J, Bourke GJ: The role of tobacco and alcohol in the aetiology of lung and larynx cancer. $\mathrm{Br} \mathrm{J}$ Cancer 46:961-964, 1982

6. Schmeltz I. Hoffmann D: Chemical studies on tobacco smoke. XXXVIII. The physicochemical nature of cigarette smoke, in Proceedings of the 3rd World Conference on Smoking and Health, DHEW Publ. (NIH) 76-1221, 1976

7. Kruysse A, Feron VJ, Til HP: Repeated exposure to acetaldehyde vapor. Studies in Syrian golden hamsters. Arch Environ Health 30:449452. 1975

8. Appelman LM, Woutersen RA. Feron VJ: Toxicity of acetaldehyde in rats. I. Acute and subacute studies. Toxicology 23:293-307, 1982
9. Obe G, Ristow H: Mutagenic, cancerogenic and teratogenic, effects of alcohol. Mutat Res 65:229-259, 1979

10. Jansson $T$ : The frequency of sister chromatid exchanges in human lymphocytes treated with ethanol and acetaldehyde. Hereditas 97:301303,1982

11. Stich HF, Rosin MP: Quantitating the synergistic effect of smoking and alcohol consumption with the mironucleus test on human mucosa cells. Int J Cancer 31:305-308, 1983

12. Baraona E, Julkunen R, Tannenbaum L, Lieber CS: Role of intestinal bacterial overgrowth in ethanol production and metabolism in rats. Gastroenterology 90:103-110, 1986

13. Pikkarainen PH, Baraona E, Jauhonen P, Lieber CS: Contribution of oropharynx microflora and of lung microsomes to acetaldehyde in expired air after alcohol ingestion. J Lab Clin Med 97:631-636, 1981

14. Jauhonen P, Baraona E, Miyakawa H, Lieber CS: Origin of breath acetaldehyde during ethanol oxidation. J Lab Clin Med 100:908-916, 1982

15. Lesser M, Chang JC, Orlowski J, Kilburn KH, Orlowski M: Cathepsin B and prolyl endopeptidase activity in rat peritoneal and alveolar macrophages. Simulation of peritoneal macrophages by saline lavage. J Lab Clin Med 101:327-334, 1983

16. Bernstein J, Martinez B, Escobales N, Santana G: The pulmonary ethanol metabolizing system (PET). Res Commun Chem Pathol Pharmacol 39:49-67, 1983

17. Sorokin SP: The cells of the lung, in Nettsheim P, Hanna MG, Jr., Deatherage JW, Jr. (eds): Morphology of Experimental Respiratory Carcinogenesis. AEC Symposium Series 21. United States Department of Commerce, Springfield, VA, 1970, pp 3-41

18. Azzopardi A, Thurlbeck WM: The histuchemistry of the nonciliated bronchiolar epithelial cells. Am Rev Respir Dis 99:516-525, 1969

19. Cutlet T, Adnet JJ, Hopfner C: Etude histo-chimique de cellules alveolaires du poumon: les cellules a inclusions lipidiques complexes. Histochemie 15:21-37, 1968

20. Devereux TR, Serabjit-Singh CJ, Slaugher SR, Wolf CR, Philpot RM, Fouts JR: Identification of cytochrome P-450 isoenzymes in nonciliated bronchiolar epithelial (Clara) and alveolar type II cells isolated from rabbit lung. Exp Lung Res 2:221-230, 1981

21. Devereux TR, Fouts JR: Xenobiotic metabolism by alveolar type II cells isolated from rabbit lung. Biochem Pharmacol 30:1231-1237, 1981

22. Seitz HK, Garro AJ, Lieber CS: Enhanced pulmonary and intestinal activation of procarcinogens and mutagens after chronic ethanol consumption in the rat. Eur $\mathrm{J}$ Clin Invest 11:33-38, 1981

23. Hook GER, Bend JR, Fouts JR: Mixed-function oxidases and the alveolar macrophage. Biochem Pharmacol 21:3267-3277, 1972

24. Korsten MA, Matsuzaki S, Feinman L, Lieber CS: High blood acetaldehyde levels after ethanol administration: Differences between alcoholic and non-alcoholic subjects. New Engl J Med 292:386-389, 1975 
In summary, results presented in this and the preceding paper,' showing that ethanol has definite effects upon neocortical processes of inhibition and excitation, should not be interpreted as establishing a basis for "disinhibition of the cortex under alcohol." The measures studied in these experiments show biphasicity of effects, tolerance, and differences under acute and chronic treatments. The cortical systems studied are involved in the complex organization and control of motor expression. Our results point to ethanol's effects upon more specific cortical functions than have been studied to date. For the human condition of acute ethanol effects upon motor expression, we view our data as suggesting that ethanol intake beyond a certain low level leads to a loss of one component of cortical organization and control, recurrent inhibition, rather than simply decreasing some kind of general functional inhibition. We also suggest that, at least in the initial stages of chronic alcohol intake, humans may reacquire some of the previously blocked neocortical mechanisms of motor control.

\section{ACKNOWLEDGMENT}

Grateful thanks are extended to David Tellner for his technical assistance.

\section{REFERENCES}

1. Rutledge LT, Chi S-I, Sunter MA: Effects of acute ethanol administration on neocortical inhibition. Alcohol Clin Exp Res 10:506-511, 1986

2. Lake N, Yarbrough GG, Phillis JW: Effects of ethanol on cerebral cortex neurons: Interactions with some putative transmitters. J Pharm Pharmacol 25:582-584, 1973

3. Wayner MJ, Ono T, Nolley D: Effects of ethyl alcohol on cortical neurons. Pharmacol Biochem Behav 3:499-506, 1975

4. Klemm WR, Mallari CG, Dreyfus LR, Fiske JC, Forney E, Mikeska JA: Ethanol-induced regional and dose-response differences in multiple-unit activity in rabbits. Psychopharmacology 49:235-244, 1976

5. Chapin JK, Woodward DJ: Ethanol's effect on selective gating of somatic sensory inputs to single cortical neurons. Pharmacol Biochem Behav 18:489-493, 1983

6. Nestoros JN: Ethanol specifically potentiates GABA-mediated neurotransmission in feline cerebral cortex. Science 209:708-710, 1980

7. Nestoros JN: Ethanol selectively potentiates GABA-mediated inhibition of single feline cortical neurons. Life Sci 26:519-523, 1980

8. Kunz G, Englisch H-J, Wenzel J: Untersuchungen zur SpinesVerteilung an Pyramidenneurones der CA I-region des Hippocampus der Ratte nach langzeitiger oraler Alkoholapplikation. J Hirnforsch 17:351363,1977

9. Schulz E, Schönheit B: Quantitative Untersuchung über apikale Dendriten-Spines an cingulären Lamina-V-Pyramiderneuronen der Ratte nach oraler Alkohol-Applikation. Z Mikrosk Anat Forsch 91:453459, 1977

10. Walker DW, Barnes DE, Zornetzer SF, Hunter BE, Kubanis P:
Neuronal loss in hippocampus induced by prolonged ethanol consumption in rats. Science 209:711-713, 1980

11. Lee K, Dunwiddie T, Deitrich R, Lynch G, Hoffer B: Chronic ethanol consumption and hippocampal neuron dendritic spines: a morphometric and physiological analysis. Exp Neurol 71:541-549, 1981

12. Tavares MA, Paula-Barbosa MM, Gray EG: Dendritic spine plasticity and chronic alcoholism in rats. Neurosci Lett 42:235-238, 1983

13. McMullen PA, Saint-Cyr JA, Carlen PL: Morphological alterations in rat CAl hippocampal pyramidal cell dendrites resulting from chronic ethanol consumption and withdrawal. J Comp Neurol 225:111118,1984

14. Lescaudron L, Verna A: Effects of chronic ethanol consumption on pyramidal neurons of the mouse dorsal and ventral hippocampus: a quantitative histological analysis. Exp Brain Res 58:362-367, 1985

15. Popova EN: Changes of cortical neuron dendrites during experimental alcohol intoxication. Biull Eksp Biol Med 85:87-89, 1978

16. Karwacka H: Ultrastructural and biochemical studies in brain and other organs in rats after chronic alcohol administration. Exp Pathol 18:127-135, 1980

17. Krnjević K, Randić M, Straughan DW: An inhibitory process in the cerebral cortex. J Physiol (Lond) 184:16-48, 1966

18. Anderson TE, Rutledge LT, Dyer RS: Altered neuronal excitability accompanyng experimental prevention of supersensitivity in undercut cortex. Brain Res 95:147-153, 1975

19. Dörrscheidt GA: The statistical significance of the peristimulus time histogram (PSTH). Brain Res 220:397-401, 1981

20. Crow EL, Gardner RS: Confidence intervals for the expectation of a Poisson variable. Biometrika 46:441-453, 1959

21. Pearson ES, Hartley HO (eds): Biometrical Tables for Statisticians, vol I, 3rd ed. Cambridge, Cambridge University Press, 1966

22. Scheibel ME, Scheibel AB: The methods of Golgi, in Robertson RT (ed): Neuroanatomical Research Techniques. New York, Academic Press, 1978, pp 89-114

23. Krauth J: The interpretation of significance tests for independent and dependent samples. J Neurosci Methods 9:269-281, 1983

24. Krnjević K, Randic M, Straughan DW: Nature of a cortical inhibitory process. J Physiol (Lond) 184:49-78, 1966

25. McLennan $H$ : Inhibitions of long duration in the cerebral cortex. A quantitative difference between excitatory amino acids. Exp Brain Res 10:417-426, 1970

26. Davidoff RA: Alcohol and presynaptic inhibition in an isolated spinal cord preparation. Arch Neurol 28:60-63, 1973

27. Grupp L: Biphasic action of ethanol on single units of the dorsal hippocampus and the relationship to the cortical EEG. Psychopharmacology 70:95-103, 1980

28. Walker DW, Hunter BE, Wickliffe C, Abraham BA: Neuroanatomical and functional deficits subsequent to chronic ethanol administration in animals. Alcohol Clin Exp Res 5:267-282, 1981

29. Durand D, Carlen PL: Decreased neuronal inhibition in vitro after long-term administration of ethanol. Science 224:1359-1361, 1984

30. Kalant H, LeBlanc AE, Gibbins RJ, Wilson A: Accelerated development of tolerance during repeated cycles of ethanol exposure. Psychopharmacology 60:59-65, 1978

31. Juntunen J, Widenius $T$, Reed TE, Ylikahri $R$, Matikainen $E$, Sarviharju $M$, Teräväinen $H$ : Tolerance for the decrease in nerve conduction velocity and for the motor impairment produced by ethanol in mice: differential development during chronic ethanol consumption. Neurobehav Toxicol Teratol 6:245-248, 1984

32. Winger JR, Tiffany TM, Bombardier C, Nicholls K, Woods SC: Ethanol tolerance in the rat is learned. Science 213:575-577, 1981 